\title{
Adenosine Receptors Mediated Intracellular Calcium in Cumulus Cells Involved in the Maintenance of First Meiotic Arrest
}

\author{
Heekyung Hwang and ${ }^{\dagger}$ Yong-Pil Cheon \\ Division of Development and Physiology, Department of Biology, Institute for Basic Sciences, \\ Sungshin Women's University, Seoul 136-742, Republic of Korea
}

\begin{abstract}
Keeping the intact germinal vesicle (GV) is essential for maintaining the capacity of mammals including human. It is maintained by very complex procedures along with folliculogenesis and is a critical step for getting competent oocyte. So far, a few mechanisms involved in folliculogenesis are known but GV arrest mechanisms are largely unrevealed. Cyclic AMP, a adenosine derived substance, have been used as inhibitor of germinal vesicle breakdown as a putative oocyte maturation inhibitor. In this study, we examined the potency of adenosine as GV maintainer and a possible signaling mediator for that. $\mathrm{A} 1, \mathrm{~A} 2 \mathrm{~b}$, and $\mathrm{A} 3$ were detected in cumulus cells of cumulus enclosed-oocyte (CEO). Intact of germinal vesicle was not kept like in follicle but the spontaneous maturation was inhibited by exogenous adenosine. It is inhibited with concentration dependent manners. Intracellular calcium level of cumulus was extensively increased after adenosine treatment. Based on these results it is suggested that one of the pathway for GV arrest by adenosine and its receptors is calcium mediated signaling pathway in CEO.
\end{abstract}

Key words : Meiotic arrest, Adenosine, Calcium, Cumulus cell

\section{INTRODUCTION}

The developmental ability of oocyte is dependent on various factors including size, accumulation of nutrients and other factors including developmental determinant factors. To get the developmental potency, the growing oocytes should be stay in GV intact status, prophase I of meiosis and growth to a species-specific size. The meiotic cell cycle in mammalian oocytes proceeds up to the dictiate stage of the first prophase. Although dictiate stage arrest (GV arrest) is critical in gametogenesis, only few of cellular molecules are known to be involved in $\mathrm{GV}$ arrest during oogenesis.

A few of cellular molecules are known to be involved in GV arrest during oogenesis. In vitro condition, spontaneous maturation of denuded oocyte (DO) and cumulusenclosed oocyte (CEO) can be inhibited or delayed by cyclic adenosine monophosphate (cAMP) which are injection of 3',5'-adenosine monophosphate (Tsafriri et al., 1972), folskolin induced activation of adenylate cyclase (Ekholm, 1984), follicle stimulating hormone (FSH, Eppig et al., 1983), etc.. Co-treatment of FSH and adenosine $(1-30 \mu \mathrm{M})$ markedly inhibits the germinal vesicle breakdown (GVB) of CEOs in a dose-dependent manner (Miller \& Behrman, 1986).

The spontaneous resumption of meiosis after removed from the intrafolliclular environment is not affected by the concentration of external calcium in the absence of

\footnotetext{
Manuscript received 29 May 2013, received in revised form 15 June 2013, accepted 20 June, 2013

${ }^{\dagger}$ Corresponding Author : Yong-Pil Cheon, Division of Development and Physiology, Department of Biology, Institute for Basic Sciences, College of Natural Sciences, Sungshin Women's University, 249-1 Dongseon-dong 3-ga, Seongbuk-gu, Seoul 136-742, Republic of Korea. Tel. : +82-2-920-7639, Fax : +82-2-920-2093, E-mail : ypcheon@sungshin.ac.kr

This is an Open Access article distributed under the terms of the Creative Commons Attribution Non-Commercial License(http:// creativecommons. org/licenses/by-nc/3.0) which permits unrestricted non-commercial use, distribution, and reproduction in any medium, provided the original work is properly cited.
} 
dibutyryl cyclic AMP (dbcAMP): GVB was unaffected by the calcium ionophore $\mathrm{A} 23187$, the calcium antagonists verapamil or tetracaine, and calcium-depleted medium (Paleos \& Powers, 1981). However, in the presence of FSH, adenosine inhibits calcium-induced oocyte maturation in CEO but those have no effects on that in denuded oocytes (Preston et al., 1987). Therefore it has been suggested that the action of dbcAMP is mediated by its effect upon this calcium (Powers \& Paleos, 1982). The activation of MPF is necessary for store-operated $\mathrm{Ca}^{2+}$ entry (SOCE) inactivation during oocyte maturation (Machaca \& Haun, 2002). On the other hand, inositol 1,4,5-triphosphate $\left(\mathrm{IP}_{3}\right)$ receptor sensitivity is increased at the time of MPF activation and $\mathrm{IP}_{3}$-dependent $\mathrm{Ca}^{2+}$ release needed for MPF activation (Sun et al., 2009). Calmodulin antagonist inhibit GVB (Carroll \& Eckberg, 1986).

On the other hand, a few of molecules were studied to explain the long time GV arrest during oocyte growth. Early mitotic inhibitor 1 (Emil)-dependent regulation of $\mathrm{APC}^{\mathrm{cdh} 1}$ is essential for regulating prophase I arrest. The destruction of Emil delays entry into meiosis 1 and prevents normal M1 spindle formation in mouse oocyte (Marangos et al, 2007; Reis et al., 2006). APC activity that is involved in inactivation of MPF is modulated by PIK and PKA (Kotani et al., 1998). A-kinase anchoring proteins (AKAPs) mediate the intracellular localization of PKA and control the specificity and kinetics of substrate phosphorylation. APAP/PKA interactions maintain the GV arrest (Newhall et al., 2006). Natriuretic peptide precursor type C (NPPC) acting via natriuretic peptide receptor 2 (nPR2) maintain meiotic arrest (Zhang \& Xia, 2012).

The synergism of adenosine with forskolin on meiotic arrest does not require uptake of the nucleoside nor its conversion to ATP and that adenosine effects are exerted at the level of the oocyte plasma membrane (Salustri et al., 1988). The meiotic blocking of hypoxanthine plus adenosine is reversed by uptake the adenosine in denuded oocyte and it is suggested that the action of adenosine is not due to hypoxanthine salvage pathway (Downs, 1999). In addition, the putative metabolite cAMP plays an im- portant role in controlling meiotic arrest of oocytes in most species studied. Elevated cyclic AMP levels in defolliculated oocytes to the same extent as in follicular oocytes. However, it is not enough to explain the complex results of adenosine in meiotic arrest.

Purine can work in the cells which express its receptors. Adenosine can work through its receptors on plasma membrane. Adenosine receptor has four subtypes, A1, $\mathrm{A} 2 \mathrm{~A}, \mathrm{~A} 2 \mathrm{~B}$ and $\mathrm{A} 3$. All of these subtypes belong to the superfamily of G protein-coupled receptors (GPCRs), with the $\mathrm{A} 1$ and $\mathrm{A} 3$ adenosine receptors interacting with pertussis toxin (PTX)-sensitive $\mathrm{G}$ proteins, including $\mathrm{Gi}$ and $\mathrm{Go}(\mathrm{Gi} / \mathrm{o})$ proteins, and the $\mathrm{A} 2 \mathrm{~A}$ and $\mathrm{A} 2 \mathrm{~B}$ adenosine receptors interacting with Gs protein (Epperson et al., 2009). It means that adenosine can induce various cellular signaling pathways through its receptors.

Although adenosine involve in blocking of meioitic division depending on the conditions, the mechanisms are not clear. Based on them it is hypothesized that adenosine may involve in $\mathrm{GV}$-arrest through adenosine receptors of cumulus cells. Therefore in this study, we investigate that adenosine has interaction with cumulus during oocyte meiotic arrest and that express adenosine receptor aspect in cumulus enclosed oocyte.

\section{MATERIAL METHOD}

\section{Animals and oocytes collection}

All experiments involving animals were conducted in accordance with the National Institutes of Health standards for the use and care of animals. The animal protocols were approved by the Sungshin Women's University Institutional Animal Care and Use Committee. CD-1 mice were maintained on a $14 \mathrm{~h}$ light and $10 \mathrm{~h}$ dark cycle under standard vivarium conditions, and supplied with food and water ad libitum. Immature female mice (3 weeks old) were injected with 5 units of gonadotropin from pregnant mares' serum (PMSG) to enhance multiple follicular developments. The mice were sacrificed by cervical dislocation at $46 \mathrm{~h}$ post PMSG injection. Then 
their ovaries were removed and transferred to BWW medium (94.6 mM NaCl, $4.78 \mathrm{mM} \mathrm{KCl}, 1.19 \mathrm{mM} \mathrm{KH}_{2} \mathrm{PO}_{4}, 1.19$ $\mathrm{mM} \mathrm{MgSO}_{4} \cdot 7 \mathrm{H}_{2} \mathrm{O}, 1.71 \mathrm{mM}$ calcium lactate, $21.58 \mathrm{mM}$ sodium lactate, $0.3 \mathrm{mM}$ sodium pyruvate, $25.07 \mathrm{mM}$ $\mathrm{NaHCO}_{3}, 100$ units $/ \mathrm{ml}$ penicillin, $100 \mu \mathrm{g} / \mathrm{ml}$ streptomycin, $\mathrm{pH} 7.4$, and $0.4 \%$ BSA). Oocytes were collected by ovarian follicular puncture with needle under a dissecting microscope and collected the CEO. All this procedure did within 20 minutes for escape spontaneous maturation. Only healthy immature oocytes were chosen for culture.

\section{Culture of oocytes and treatment with adenosine}

Oocytes were cultured in $10 \mu \mathrm{l}$ drops of BWW medium under the mineral oil (Sigma) for $18 \mathrm{~h}$ at $37^{\circ} \mathrm{C}$ in a humidified $\mathrm{CO}_{2}$-controlled (5\%) incubator. To study the effects of the adenosine on oocyte maturation, immature oocytes were cultured in BWW contained 50 or $750 \mu \mathrm{M}$ adenosine. It is known that the concentration of adenosine is $750 \mu \mathrm{M}$ in follicular fluid. The maturation stages were scored with a differential interference contrast microscope (Carl Zeiss, Germany).

\section{RT-PCR}

cDNA systhesis was used sidestep ${ }^{\mathrm{TM}}$ QPCR cDNA synthesis Kit. For A1, the forward and reverse primers were 5'-GTCTCTGTGCCCGGAAATGTAC-3' and 5'CGTGTGTGAGGAAGATGGCAAT-3'3', which amplified a fragment of . For A2a, the forward and reverse primers were 5'-GCAACCTGCAGAACGTCACAA-3' and 5'-TC TGTCTGACTGCAGTTGTTCCAG-3'. For A2b, the forward and reverse primers were 5'-TGTCGACCCGATA TCTGCCAT-3' and 5'-CATCAGTTCCATGCGCTGAAG -3 '. For $A 3$, the forward and reverse primers were 5'TCTGAGGACCACCACCGTCTATTT-3' and 5'-GGAT CCAGGTGATGAAGCTGAAA-3'.

\section{Measurement of intracellular $\left[\mathrm{Ca}^{2+}\right]$}

Intracytoplasmic free calcium levels were monitored by a laser scanning confocal microscope. Follicular puncture did in the BWW medium containing $5 \mu \mathrm{M}$ Fluo 3-AM and the CEO were further incubated for $15 \mathrm{~min}$ in the medium containing $5 \mu \mathrm{M}$ Fluo 3-AM. After then, the CEO was washed five times with plane medium. The oocytes were seized between slide glass and coverslip using dot-slide and scanned every $2.1 \mathrm{~s}$ at $37^{\circ} \mathrm{C}$ under the laser scanning confocal microscope (Olympus, Fluo View). The results were expressed as the relative fluorescence intensity (RFI).

\section{Statistical analysis}

Chi-squared test was used in statistical analysis, and a $\mathrm{P}$ value less than 0.05 was considered significant.

\section{RESULT}

\section{Adenosin helped GV arrest in CEO}

In control medium, $95 \%$ of the CEOs spontaneously released from $\mathrm{GV}$-intact condition within $6 \mathrm{hr}$ after release from the preovulatory follicle (Fig. 1). In the media containing $50 \mu \mathrm{M}$ adenosine, the rate of GV-intact oocytes was increased but there was no statistical significance compared with the control until $1.5 \mathrm{hr}$ after culture. After then, the rates of GV-intact were significantly high at 3

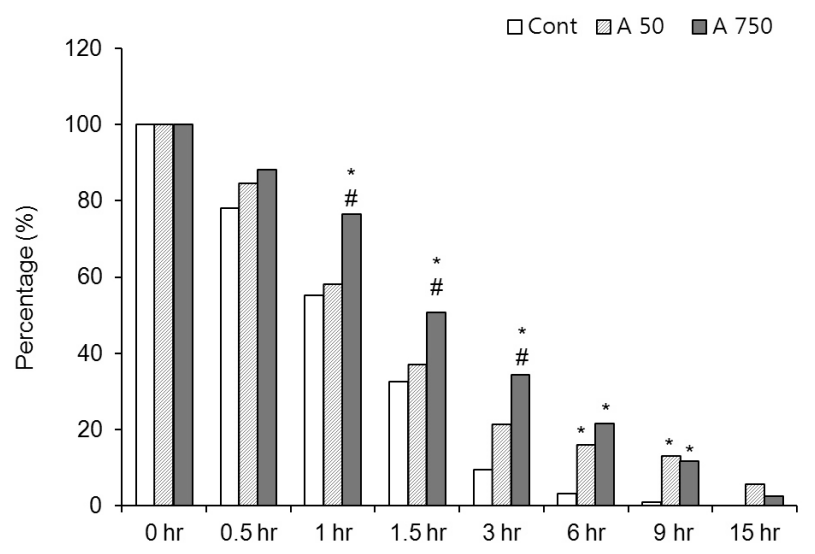

Fig. 1. Effect of adenosine on the in vitro maturation of the cumulus enclosed oocytes. Cumulus enclosed-immature oocytes were treated with $5 \mu \mathrm{g}$ and $750 \mu \mathrm{g}$ adenosine. It is known that the concentration of adenosine in the follicular fluid is $750 \mu \mathrm{M}$. *, significantly different from control at $P<0.05$; \#, significantly different from between 5 and $750 \mu \mathrm{g}$ treatment groups. 
hr $(9.4 \%$ vs $21.4 \%), 6 \mathrm{hr}(3.1 \%$ vs $15.9 \%)$ and $9 \mathrm{hr}$ $(0.8 \%$ vs $11.6 \%)$ compared with the control. In $750 \mu \mathrm{M}$ adenosine treated group, the arresting is kept longer than $50 \mu \mathrm{M}$ group. The rates of $\mathrm{GV}$-intact oocytes were significantly high compared with the control until $9 \mathrm{hr}$ after culture. In $750 \mu \mathrm{M}$ group, the rates of $\mathrm{GV}$-intact were significantly high at $1 \mathrm{hr}(58.1 \%$ vs $76.5 \%), 1.5 \mathrm{hr}$ (37\% vs $50.7 \%)$ and $3 \mathrm{hr}(21.4 \%$ vs $34.3 \%)$, but after then there was no significance compared with those of $50 \mu \mathrm{M}$ adenosine group (Fig. 1). Those data means $\mathrm{GV}$-arresting effect of adenosine is lasting until $9 \mathrm{hr}$ and it is direct proportional to the concentration of adenosine.

\section{Expression patterns of adenosine receptors during} maturation induction and follicular genesis

To evaluate the working pathway of adenosine, we tried to identify the existence of adenosine receptor(s) in CEO. A1 receptor was detected in CEO at $9 \mathrm{hr}$. A2b also detected in CEO in all time points (Fig. 2). These results explain that $\mathrm{A} 1$ and $\mathrm{A} 2 \mathrm{~b}$ receptors are expressed in the cumulus and those are spatio-temporally expressed $9 \mathrm{hr}$ after released from follicle. In the case of $\mathrm{A} 2 \mathrm{a}$, it was not detected in all the groups. A3 was detected in CEO at $0 \mathrm{hr}$ and $9 \mathrm{hr}$ time points after released from follicles (Fig. 2). It means that cumulus cell expresse A3 in a time-dependent manner.

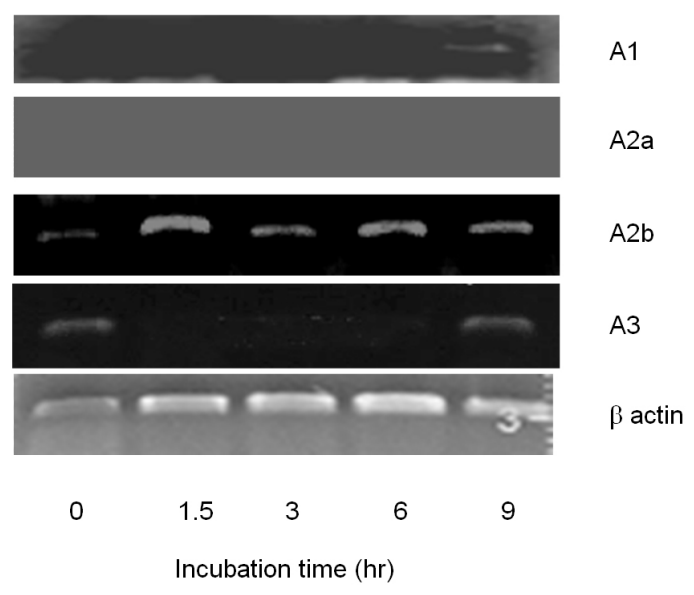

Fig. 2. Expression of adenosine receptors in cumulus enclosed oocytes. Adenosine receptors were identified with RT-PCR.

\section{Modulation of the intracellular free calcium level} in CEO by adenosine

A1 activation promotes an increase on alpha(2)adrenoreceptor binding in brainstem cell through phospholipase $\mathrm{C}$, protein kinase $\mathrm{Ca}^{2+}$-dependent, $\mathrm{IP}_{3}$ receptor and intracellular calcium (Carrettiero et al., 2009). A2bR couple to $\mathrm{G}(\mathrm{s})$-adenylyl cyclase and its agonist elevates cellular cAMP and stimulates extracellular signal-regulated kinase 1/2 activity (Epperson et al., 2009). In nucleus tractus solitary (NTs), phospholipase C, protein kinase $\mathrm{Ca}^{2+}$-dependent, $\mathrm{IP}_{3}$ receptor and intracellular calcium is participate in $\mathrm{A} 2 \mathrm{aR}$ and $\mathrm{A} 1 \mathrm{R}$ interaction (Carrettiero et
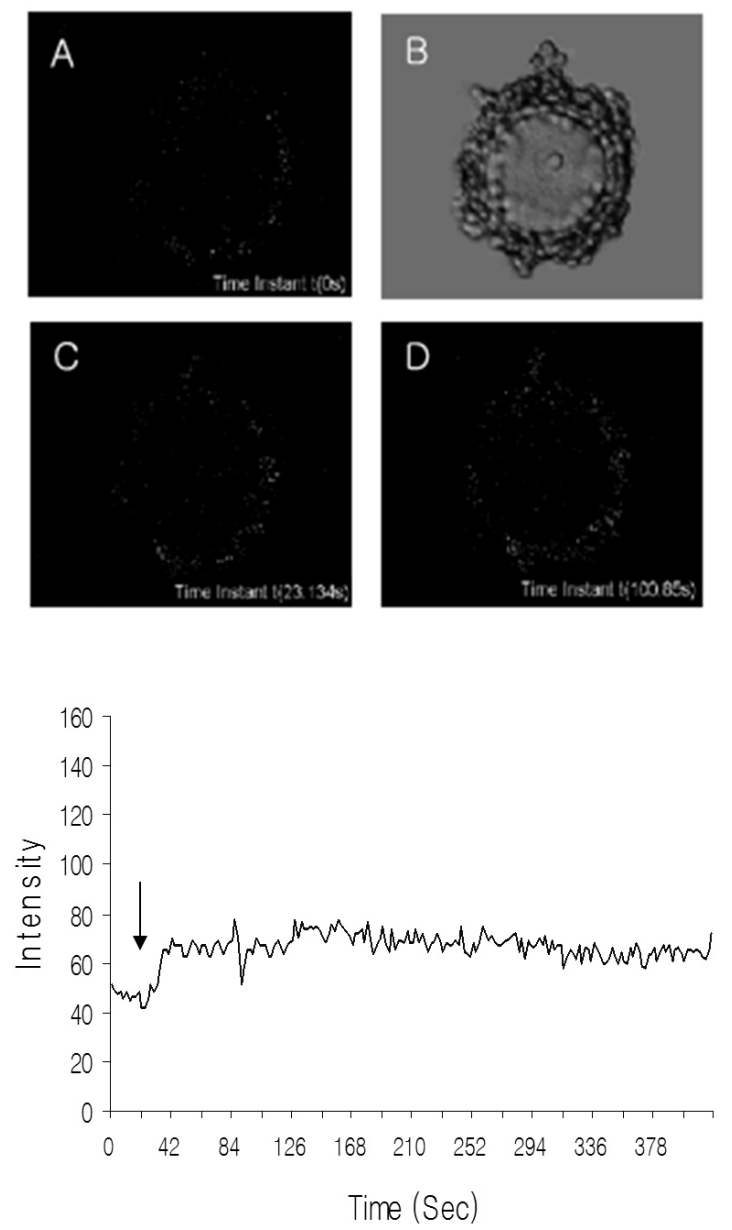

Fig. 3. Intracellular free $\mathrm{Ca}^{2+}$ fluctuation in the cumulus by adenosine. PMSG-primed cumulus enclosed oocytes (B) were collected at $46 \mathrm{hr}$ and treated with adenosine (750 $\mu \mathrm{M})$. Free calcium was measured using Fura-3 AM (5 $\mu \mathrm{M}$, Molecular Probe). A: $0 \mathrm{sec}, \mathrm{C}: 24 \mathrm{sec}, \mathrm{D}: 100.85 \mathrm{sec}$. 
al., 2009). A3 does not induce the calcium uptake in the mitochondria (Xia et al, 2007) but it involved in $\left[\mathrm{Ca}^{2+}\right] \mathrm{i}$ fluctuation in BON cell. From them we know that calcium is indirectly involved in signaling of adenosine receptors.

To know whether the adenosine can work with calcium in GV arrest, the level of free calcium was measured as mentioned in Materials and Methods. Calcium levels were increased by adenosine treatment in cumulus cell within a few seconds as shown in Fig. 3. In the case of oocytes, the levels of calcium were not changed dramatically and its small fluctuations appeared about 70 seconds after adenosine treatment. These results suggest that A3 may regulate the calcium levels directly in cumulus cell and indirectly in oocytes. Also, those results revealed that calcium is not direct regulator of $\mathrm{GV}$ arrest.

\section{DISCUSSION}

Adenosine is an important regulator of cellular function, being released by numerous cells under a variety of conditions to act in paracrine or autocrine capacity. It can induce cellular response through its membrane receptors. All the adenosine receptor subtypes belong to the superfamily of $G$ protein-coupled receptors (GPCRs) (Kobayashi et al., 2002). Affinity to the adenosine of these receptors is difference between them and the effects of adenosine depend on their concentration. In here we showed that adenosine delay GVB and keep GV-intact during a limited time.

So far the roles of adenosine in meiotic arrest are controversy. One of the possible roles is adenosine potentiates the meiotic arrest induced by FSH in CEO (Downs, 1999). Downs and Chen (2006) reported that native adenosine has meiosis-inducing capability. When tested various culture conditions, meiotic induction by 8-bromo-adenosine (8-Br-Ado) and a second adenosine analog, methyl-mercaptopurine riboside (MMPR), was especially potent in denuded oocytes (D) compared to CEO and was not dependent on the type of inhibitor chosen to maintain meiotic arrest. Adesnosine and inhibitors of de novo purine synthesis had no effect on the completion of maturation (Downs \& Chen, 2006). It also known that the concentration of purines in follicular fluid are not same between follicular stages. Interestingly, in our results, we could get following results; adenosine bolocked the GVB in a concentration dependent manners in a restricted period in in vitro. In the case of adenosine treated groups, the rates of GV-arrest was significantly higher in CEO groups until $9 \mathrm{hr}$ post in vitro culture. GV-arresting effect of adenosine is lasting until $9 \mathrm{hr}$ and is direct proportional to the concentration of adenosine. It is revealed that during folliculogenesis the adenosine can inhibit GVB through cumulus cells and that adenosine may work through cumulus cells to GV arrest in higher concentration.

Adenosine treatment together with forskolin produces a further delay in the resumption of meiosis. Dipyridamole, which inhibits adenosine transport, does not prevent the meiosis-arresting synergistic effect of adenosine with forskolin (Salustri et al., 1988). As seen the results, adenosine delay the resumption of meiosis. In addition, during in vitro maturation there adenosine receptors expressed time dependently. These mean that adenosine works through its receptors on the cumulus cells to delay the meiotic resumption.

The follicular fluid contains the purines, $2-4 \mathrm{mM}$ hypoxanthine and $0.34-0.78 \mathrm{mM}$ adenosine, and that the concentrations of these purines decrease immediately before gonadotropin-induced germinal vescle breakdown (Eppig et al., 1985). In the case of porcine, follicular fluid contains hypoxanthine $(1.4 \mathrm{mM})$, adenosine $(0.06$ $\mathrm{mM})$, uracil $(0.44 \mathrm{mM})$, and 7-methyliosine $(0.19 \mathrm{mM})$. The hypoxanthine contribute significantly to the maturationarresting activity of porcine follicular fluid (Downs et al., 1985). Put together with our results, it is suggested that adenosine in the follicular fluid may control the meiotic resumption through its receptors on cumulus cells.

So far, calcium is known as a meiosis regulator for prophase 1 arrest in oocyte. Increase the free calcium in oocyte is needed in activation of MPF (Machaca and 
Haun, 2002; Powers and Paleos, 1982; Sun et al., 2009). In the cumulus cells, however, the role of calcium in meiotic arrest is not much known. In here we revealed that the free calcium levels were increased by exposing to adenosine. Put together with the suppression effects on meiotic resumption of adenosine, this result means that the calcium increase in cumulus cells involved the regulation of meiotic arrest.

At 1988 Salustri and his colleagues suggested that adenosine effects are exerted at the level of the oocyte plasma membrane. In here we showed that adenosine also suppress meiotic resumption through it receptors on the cumulus cells. In addition, it is suggested that the increased calcium levels in cumulus by adenosine may involve in the meiotic regulation by cumulus cells, even though the further studies are needed.

\section{ACKNOWLEDGEMENT}

This study was supported by a grant from the Sungshin Women's University (2013). None of the authors are involved in any potential financial conflicts of interest.

\section{REFERENCES}

Carroll AG, Eckberg WR (1986) Inhibition of germinal vesicle breakdown and activation of cytoplasmic contractility in Spisula oocytes by calmodulin antagonist. Biol Bull 170:43-50.

Downs SM (1999) Uptake and metabolism of adenosine mediate a meiosis-arresting action on mouse oocytes. Mol Reprod Dev 53:208-221.

Downs SM, Chen J (2006) Induction of meiotic maturation in mouse oocytes by adenosine analogs. Mol Reprod Dev 73:1159-1168.

Downs SM, Coleman DL, Ward-Bailey PF, Eppig JJ (1985) Hypoxanthine is the inhibitor of murine oocyte maturation in a low molecular weight fraction of porcine follicular fluid. Proc Natl Acad Sci USA 82:454-458.

Ekholm C, Hillensjo T, Magnusson C, Rosburg S (1984)
Stimulation and inhibition of rat oocyte meiosis by forskolin. Biol Reprod 30: 5 37-43.

Epperson SA, Brunton LL, Ramirez-Sanchez I, Villarreal F (2009) Adenosine receptors and second messenger signaling pathways in rat cardiac fibroblasts. Am J Physiol Cell Physiol 296:C1171-C1177.

Eppig JJ, Feter EF, Ward-Bailey PF, Schultz RM (1983) Inhibition of oocyte maturation in the mouse: participation of cyclic AMP, steroids, and a putative maturation inhibitory factor. Dev Biol 100:39-49.

Eppig JJ, Ward-Bailey PF, Coleman DL (1985) Hypoxanthine and adenosine in murine ovarian follicular fluid: concentrations and activity in maintaining oocyte meiotic arrest. Biol Reprod 33:1041-1049.

Kobayashi T, Ikeda K, Kumanishi T (2002) Functional characterization of an endogenous Xenopus oocyte adenosine receptor. Br J Pharmacol 135:313-322.

Kotani S, Tuendreich S, Fujii M, Jorgensen PM, Watanabe N, Hoog C, Hieter P, Todokoro K (1998) PKA MPFactivated Polo-like kinase regulate anatphase-promoting complex activity and mitosis progression. Mol Cell $1: 371-380$.

Machaca K, Haun S (2002) Induction of maturationpromoting factor during Xenopus oocyte maturation uncouples $\mathrm{Ca}^{2+}$ store depletion from store-operated $\mathrm{Ca}^{2+}$ entry. J Cell Biol 156:75-86.

Marangos P, Verschuren EW, Chen R, Jackson PK, Carroll J (2007) Prophase I arrest and progression to metaphase I in mouse oocytes are controlled by Emil-dependent regulation of $\mathrm{APC}(\mathrm{Cdh} 1)$. J Cell Biol 176:65-75.

Miller JG, Behrman HR (1986) Oocyte maturation is inhibited by adenosine in the presence of folliclestimulating hormone. Biol Reprod 35:833-837.

Newhall KJ, Criniti AR, Cheah CS, Smith KC, Kafer KE, Burkart AC, McKnight GS (2006) Dynamic anchoring of PKA is essential during oocyte maturation. Curr Biol 16:321-327.

Paleos GA, Powers RD (1981) The effect of calcium on the first meiotic division of the mammalian oocyte. J Exp Zool 217:409-416. 
Powers RD, Paleos GA (1982) Combined effects of calcium and dibutyryl cyclic AMP on germinal vesicle breakdown in the mouse oocyte. J Reprod Fertil 66:1-8.

Preston SL, Parmer TG, Behrman HR (1987) Adenosine reverses calcium-dependent inhibition of follicle-stimulating hormone action and induction of maturation in cumulusenclosed rat oocytes. Endocrinology 120:1346-1353.

Reis A, Chang HY, Levasseur M, Jones KT (2006) APcdh1 activity in mouse oocytes prevents entry into the first meiotic division. Nat Cell Biol 8:539-540.

Salustri A, Petrungaro S, Conti M, Siracusa G (1988) Adenosine potentiates forskolin-induced delay of meiotic resumption by mouse denuded oocytes: evidence for an oocyte surface site of adenosine action. Gamete Res 21:157-168.

Sun L, haun S, Jones RC, Edmondson RD, Machaca K
(2009) Kinase-dependent regulation of inositol 1,4,5triphosphate-dependent $\mathrm{Ca}^{2+}$ release during oocyte maturation. J Biol Chem 284:20184-20196.

Tsafriri A, Lindner HR, Zor U, Lamprecht SA (1972) In vitro induction of meiotic division in follicle enclosed rat oocytes by $\mathrm{LH}$, cyclic AMP, and prostaglandin E2. J Reprod Fertil 31:39-50.

Xia Y, Javadov S, Gan TX, Pang T, Cook MA, Karmazyn M (2007) Distinct KATP channels mediate the antihypertrophic effects of adenosine receptor activation in neonatal rat ventricular myocytes. J Pharmacol Exp Ther 320:14-21.

Zhang M, Xia G (2012) Hormonal control of mammalian oocyte meiosis at diplotene stage. Cell Mol Life Sci 69:1279-1288. 